\title{
Pointwise convergence along a tangential curve for the fractional Schrödinger equation with $0<\mathrm{m}<1$
}

\author{
Jiye Yuan $^{1}$ and tengfei Zhao ${ }^{2}$ \\ ${ }^{1}$ The Graduate School of China Academy of Engineering Physics \\ ${ }^{2}$ University of Science and Technology Beijing School of Mathematics and Physics
}

April 7, 2021

\begin{abstract}
In this article, we study the pointwise convergence problem about solution to the fractional Schrödinger equation with $0<\mathrm{m}$ $<1$ along the tangential curve and estimate the capacitary dimension of the divergence set. We extend the results of Cho and Shiraki in [8] for the case $\mathrm{m}>1$ to the case $0<\mathrm{m}<1$, which is sharp up to the endpoint.
\end{abstract}

\section{Hosted file}

pointwise-convergence-along-tangential-curve-m-4.pdf available at https://authorea.com/ users/406257/articles/516980-pointwise-convergence-along-a-tangential-curve-for-thefractional-schr\%C3\%B6dinger-equation-with-0-m-1

\section{Hosted file}

pointwise-convergence-along-tangential-curve-m-4.tex available at https://authorea.com/ users/406257/articles/516980-pointwise-convergence-along-a-tangential-curve-for-thefractional-schr\%C3\%B6dinger-equation-with-0-m-1 